\title{
Socio-Demographic and Clinical Predictor Variables on CD4 Cell Count Change among HIV Positive adults; a Structural Equations Modelling
}

Awoke Seyoum ( $\sim$ bisrategebrail@yahoo.com )

Bahir Dar University, Ethiopia

Principal Ndlovu Ndlovu

Temesgen Zewotire Zewotire

\section{Research}

Keywords: Socio-demographic, clinical factors, individual characteristics, Structural equation, CD4count change

Posted Date: January 6th, 2020

DOI: https://doi.org/10.21203/rs.2.20118/v1

License: (c) (i) This work is licensed under a Creative Commons Attribution 4.0 International License.

Read Full License 
Socio-Demographic and Clinical Predictor Variables on CD4 Cell Count Change among HIV Positive adults; a Structural Equations Modelling

1. Awoke Seyoum Tegegne ${ }^{1}$, Associate Professor (MSc), Corresponding author

Dept. of statistics, Bahir Dar University, Ethiopia

E-mail: bisrategebrail@yahoo.com

2. Principal Ndlovu' ${ }^{2}$, Professor $(\mathrm{PhD})$

Department of Statistics, University of South Africa, Pretoria, South Africa

3. Temesgen Zewotir ${ }^{3}$, professor (PhD)

School of Mathematics, Statistics and Computer Science,University of Kwazulu Natal, South Africa

${ }^{1}$ bisrategebrail@yahoo.com, Dept. of statistics, Bahir Dar University, Ethiopia

2ndlovp@unisa.ac.za, Department of Statistics, University of South Africa, Pretoria, South Africa

3 zewotir@ukzn.ac.za, School of Mathematics, Statistics and Computer Science,University of Kwazulu Natal, South Africa 


\section{ABSTACT}

Background: The prevalence of HIV/AIDS among adult individuals has been increasing in SubSahara African countries over the last decade. In Ethiopia, the prevalence of HIV among adults was 1\%. Hence, 23, 000 people were newly infected with HIV and 11,000 people were died because of AIDS related illness in 2018. The purpose of this study was to identify the most significant socio-demographic, economic, individual and clinical determinants of CD4 cell count change in HIV positive adults who initiated HAART at Felege Hiwot Teaching and Specialized Hospital, North-West Ethiopia.

Methods: A secondary and retrospective study design was conducted on 792 HIV positive adults. A structural equation modeling was employed to identify the socio-demographic and clinical covariates that have a statistically significant effect on the status of CD4 cell count change.

Results: Literate patients, patients living with partner, patients living in urban area, patients disclosed the disease to family members, high income, ownership of cell, age and sex (male) were statistically significant variables.

Conclusion: There was direct relation between socio-demographic variables with retention of HIV positive individuals in HAART program. There was also a direct and significant effect of clinical variables on adherence competence and adherence on CD4 cell change. Retention of patients in the HAART program had direct and significant effect on CD4 cell count change. This finding will be important for policy makers, health officials and for patients to easier access to healthcare service.

Keywords: Socio-demographic, clinical factors, individual characteristics, Structural equation, CD4count change 


\section{BACKGROUND}

Globally, by the end of 2018, 37.9 million people were living with human immunodeficiency virus (HIV) and Sub-Saharan Africa carries the highest burden with an estimation of $71 \%$ of the global total[1].

In Ethiopia, there were 690000 people living with HIV and HIV incidence per 1000 uninfected population over one year among all people of all ages was 0.24 . The prevalence of HIV among adults was $1 \%$. Hence, 23, 000 people were newly infected with HIV and 11,000 people were died because of AIDS related illness in 2018[2].

Among all people living with HIV, $81 \%$ of them were on treatment and $73 \%$ of them were virally suppressed, among these, $79 \%$ knew their status, $65 \%$ were on treatment. Of all adults aged 15 years and above living with HIV, $66 \%$ were on treatment and $92 \%$ of pregnant women living with HIV accessed antiretroviral medicine to prevent transmission of the virus to their baby[2]. Women are highly affected by HIV as compared to men. Hence, among 65,0000 adults living with HIV, 410 000(63.08\%) were women[3]. New HIV infections among young women aged 15-24 years were more than double those among young men (5800 new infections among young women, compared to 2000 among young men). On the other hand, HIV treatment was slightly lower among women than men, with $55 \%$ of adult women living with HIV on treatment, compared to $66 \%$ of adult men[4].

One of the measures of health status of HIV positive patients who initiated their medication is CD4 cell count change. Identifying factors affecting the level of CD4 cell count change other than ART would help health professionals and patients to facilitate proper management and monitoring of the health care intervention on individuals with highest risk (lowest CD4 cell count). Moreover, it helps to check whether HIV patients who initiated HAART based on the criteria formerly set $(<=200$ cells $/ \mathrm{mm} 3)$ are recovering to the normal range of CD4 count for the general healthy adult population $(>=500$ cells $/ \mathrm{mm} 3)[3]$.

Previous studies revealed that education is a large extent correlated with income, and much of the complexity that is evident in the relationship between income and HIV prevalence is thus also evident in the relationship between education and HIV prevalence. Relatively uneducated patients are less likely to know what AIDS is and how HIV is transmitted from one to another person[5]. 
Therefore, socio-demographic disadvantageous HIV positive adults are associated with lower CD4 cell count change [6]. The relationship between marital status and HIV infection is complex. Hence, the risk of HIV prevalence remained significantly high among unmarried compared with married people when only sexual behaviour factors are controlled for the given model[7].

The economic factors are related to level of income and ownership of cell phone. Income can be defined in terms of individual income or household income. There are a number of arguments that the relationship between income and CD4 cell count change which indicates that risk factors of HIV infection is higher among the poor, but there are also several arguments to explain why patterns of infection may be the other way around. Hence, there is controversies on findings from previous researches[8].

Nevertheless, it is likely that communities in which the average income is high are those living in the urban areas[9]. Previous researches indicate that there are economic benefits associated with maintaining high CD4 cell counts for HIV positive people [10]. In the previous research, it is indicated that patients aged 40 years and above presented lower rates of CD4 cell count change over the period of the cohort $[11,12]$.

Different researches conducted recently declared that good adherence is strongly associated with obtaining optimal CD4 cell count change compared to non-adherence[13]. The adherence level of patients are highly associated with level of income such that patients with high level of income had good competence level of food and medication adherence[14]. Thus, it is said that a person is competent when he/she uses those resources to do what is expected, as would be the case in consuming medication as prescribed [15].

Retention in HIV medication care is a crucial activity for achieving long term survival with HIV infection[16]. HIV care guideline also recognizes the importance of retention in HIV care as a precursor to adherence and a further achievement of CD4 cell count [17]. Successful strategies to improve retention in HIV care and adherence to HAART require an understanding of retention and adherence behaviour and the complex interplay between biological, psychological, behavioural, social and health system drivers $[18,19]$.

Previous researchers on predictors of CD4 cell count change used classical statistics (PROC GLM ANOVA) model. In such models, the effect of latent (unobsereved) variables on the 
variable of interest cannot be investigated. Of course, the additional contribution of latent variables can be studied in multiple regressions only if all independent variables are highly correlated with the dependent variable and uncorrelated themselves[18, 19]. The default model for the repeated measures of CD4 cell count is PROC GLM and this assumes that change is linear, constant across time, and occurs at one unit between each measurement period and that measurement occurs without errors.

On the other hand, the SEM analysis with PROC CALIS allowed for explicit representation of measurement error, and provided more information than PROC GLM[20]. In path analysis (SEM), one can see the direct, indirect and total effects of the latent variables and the model does not assume that change is constant and linear. A unique additional contribution of a latent variable has been determined in path analysis.

The longitudinal trajectories of CD4 cell count change data in current investigation were also assessed using Latent Growth Model (LGM) and Covariate Latent Growth Model (CLGM). Hence, current investigation considered path analysis conducted using AMOS software and PROC CALIS using SAS software and answered the following questions. Which social, wealth and demographic variables have statistically significant effect on the status of CD4 cell count change for HIV positive adults initiated their HAART? What is the association between predictor variables? What is association between predictors and the variable of interest (the status of CD4 cell count change)? How can we determine the shape of growth model for the variable of interest?

To investigate such questions, the hypothetical relations between variables for the prediction of CD4 cell count change have been constructed and indicated in Figure.1. The hypothetical relation suggested the direct influences of socio-demographic factors, the individual characteristics and economic factors on retention in HAART medication care and a direct association of retention in HAART medication care on HAART adherence competence. Finally, a direct influence of HAART adherence factors and retention of HAART medication care factors on CD4 cell counts change was also investigated.

Figure1 indicates the indirect effect of manifest/ observed exogenous variables like age, weight, visiting times, baseline CD4 cell count on latent variables(Socio-demographic, economic, individual and clinical variables). Socio-demographic and clinical factors also constructed to another latent variables, HAART medication care and real biological, psychological and 
HAART adherence competence. The retention in medication adherence and adherence competence are constructed to the variable of interest (CD4 cell count change). The effect of exogenous variables on the variable of interest measured based on the estimates of parameters existed between the exogenous and endogenous variables[19]. The effect of exogenous variables on the variable of interest also measured based on the amount of variance of errors committed during estimation. Hence, the values of parameters $\left(w_{1}, w_{2}, \ldots, w_{20}\right)$ was estimated. Figure 1 indicates a network of relationships of measurement model that connects the observed exogenous and endogenous variables. This was constructed using AMOS software version 22. The software computed the values of parameters $\left(w_{1}, w_{2}, \ldots, w_{20}\right)$, variance of error terms and covariance of disturbance terms $\left(\mathrm{D}_{1}, \mathrm{D}_{2}, . . \mathrm{D}_{6}\right)$.

The purpose of this study was therefore, to identify the most significant socio-demographic, economic, individual and clinical determinants of CD4 cell count change in HIV positive adults who initiated HAART and to investigate the association between these factors using SEM. The investigation also aimed to compare the results obtained by PROC GLM and PROC CALIS.

\section{Figure1:}

\section{METHODS}

Study design: The data used under current investigation consists of secondary data and a retrospective longitudinal study design was employed.

Study area and Population: The study was conducted in Felege Hiwot Teaching and Specialized Hospital, North-West Ethiopia.

Data collection procedures: Secondary data were entered and analyzed using SAS software version 9.2. For the sample to be included in the study, CD4 cell count measurement just before the initiation of HAART was considered as a covariate so that there could be at least two visit responses after the initiation of HAART for the data to be analyzed.

Quality of data: This was conducted by data controllers in ART section of the hospital. The controllers took intensive training by the Ministry of Health for this and other purposes. The reliability of variables was assessed using Cronbanch's alpha and the variables 
included in the study were tested for consistency of understanding and the completeness of the data items on75 random samples. Necessary amendments were made on the final data collection sheet. The Cronbach's alpha value for current data was 0.832 which indicates its internal consistency was good.

\section{Variables included in the study}

Response Variable: The longitudinal response variable for current study was CD4 cell count change recorded at each visiting time. CD4 cell count change was defined as the change/ or progress at each visiting time which was obtained by considering the difference between CD4 cell count at the current visit and the CD4 cell count recorded immediately before the current visit.

Predictor variables: From medical records of each HIV positive patients, individual characteristics, clinical factors, HAART adherence competence and retention in HAART medication were recorded. The individual factors were related to age of patients, sex of patients, and weight of patients. Clinical factors were related to WHO status, baseline CD4 cell count and self reported adherence measured using pill count. The real HAART adherence competence was considered as latent variable measured using clinical factors (self reported adherence, baseline CD4 cell count and WHO status). Similarly, retention in HAART medication care was another latent variable measured using time of follow up visits. Retention is defined as the time period an individual follow his/her prescribed medication.

Data analysis: Data analysis was carried out using AMOS to obtain descriptive statistics like means and standard deviations (SD). The correlation structure was also conducted to test the association of each predictor variables. Finally, using structural equation modelling, several trajectory analyses were conducted, with which we can specify the direct and indirect relationship among variables. The shape of growth model was determined, considering Latent Growth Model (LGM) and Covariate Latent Growth Model (CLGM).

\section{RESULTS:}

The study was conducted on random sample of 792 HIV positive adults who initiated their HAART at Felege Hiwot Teaching and Specialized Hospital, North-West Ethiopia. Of which 401(50.6\%) were females, 468(59.1\%) were in urban area and the rest were in rural residents.

The descriptive parameter estimates were conducted using maximum likelihood estimation technique and indicated in Table1. Table1 revealed that $|\mathrm{C} . \mathrm{R}|=\mid$ Estimates/S.E $\mid$ was greater than 
1.96 for 0.05 alpha level of confidence and greater than 2.56 for 0.01 alpha level of confidence for all covariates and this further indicates that parameter estimates for all covariates under investigation were statistically significant [26, 27].

The magnitude of mean and standard deviation for each exogenous variable in Table1 indicates that standard deviation was greater than mean for all variables and this indicates that the distribution is over-dispersed.

Table1: Mean and standard deviation of exogenous variables

\begin{tabular}{|l|c|c|}
\hline Variable & Mean & Std \\
\hline literate & 0.80965 & 0.8998 \\
\hline With partner & 0.59807 & 0.77335 \\
\hline Urban & 0.61356 & 0.7833 \\
\hline Disclosed & 0.29349 & 0.54174 \\
\hline High income & 0.13662 & 0.36962 \\
\hline Owner of cell phone & 0.55587 & 0.74557 \\
\hline age & 73.28275 & 75.13789 \\
\hline Weight & 63.71277 & 65.37255 \\
\hline Male & 0.49042 & 0.7003 \\
\hline Baseline CD4 cell count & 157.02836 & 187.47603 \\
\hline Adherent & 0.33002 & 0.57447 \\
\hline WHO not stage4 & 0.78379 & 0.88532 \\
\hline Visiting time & 11.44517 & 13.20341 \\
\hline CD4change & 28.51139 & 35.46303 \\
\hline
\end{tabular}

The magnitude of parameter estimation was conducted using AMOS version 22 and indicated in Figure2. Some of the significant variables in this model were literate patients $\left(\mathrm{w}_{1}=2.04 ; \mathrm{p}=\right.$ $0.012)$, patients living with partner $\left(\mathrm{w}_{2}=8.16 ; \mathrm{p}=0.021\right)$, patients living in urban area $\left(\mathrm{w}_{3}=3.97\right.$; $\mathrm{p}=0.024)$, patients disclosed the disease to family members $\left(\mathrm{w}_{4}=6.24, \mathrm{p}=0.012\right)$, high income $\left(\mathrm{w}_{5}=6.37 ; \mathrm{p}=0.002\right)$, ownership of cell phone $\left(\mathrm{w}_{6}=2.99, \mathrm{p}=0.034\right)$, age $\left(\mathrm{w}_{7}=-2.89, \mathrm{p}=0.001\right)$ and sex (male) $\left(\mathrm{w}_{8}=-1.25, \mathrm{p}=0.036\right)$. These significances indicate that there was direct relation between these variables and a latent variable (socio-demographic variables) and a direct association of Socio-demographic variable with retention of HIV positive individuals in HAART medication care $\left(\mathrm{w}_{14}=2.59, \mathrm{p}=0.021\right)$. 
The result also indicates that there was direct and significant association between clinical factors with baseline CD4 cell count, $\left(w_{11}=3.07 ; p=0.002\right)$, with adherence level $\left(w_{10}=3.24 ; p=0.01\right)$ with WHO stage not stage4 $\left(\mathrm{w}_{12}=2.37 ; \mathrm{p}<0.001\right)$. The longevity/retention of patients in the HAART medication care had also direct and significant effect on the competence of HAART adherence $\left(\mathrm{w}_{17}=2.31 ; \mathrm{p}<0.01\right)$.

On the other hand, the retention of patients in the HAART medication care had positive and significant effect on the achievement of CD4 cell count change ( $\left.\mathrm{w}_{18}=2.18 ; \mathrm{p}<0.01\right)$. Similarly, the HAART adherence competence also had direct and significant effect on the CD4 cell count change $\left(\mathrm{w}_{19}=3.26 ; \mathrm{p}=0.03\right)$.

In the estimation of the covariance structure, key indicators of goodness-of-fit provided that chisquare $=983.45$, with $p$-value for chi-square $<0.01$, which indicates that the chi-square statistic is not closer to zero and the corresponding p-value is very small (significant), which is an indicator of weak fit. This indicates that the model is inadequate. However, RMSEA was estimated to be $0.01, \mathrm{CFI}=0.97$, Non-normed fit index $(\mathrm{NNFI})=0.96$ and $\mathrm{NFI}=0.95$. Hence, RMSEA, CFI and NFI assured for the model to be good fit. The chi-square probability for current repeated data indicated an unacceptable model fit (chi-square $=9.101, \mathrm{df}=3, \mathrm{p}=0.028$ ).

Figure1: Path Analysis of predictor variables for CD4 cell count change after estimates of parameters and error terms.

The chi-square value is a measure of the difference between the observed and expected covariance matrices. Acceptable model fit is determined by a chi-square value close to zero and a probability value greater than $0.05[21-24,28]$.

To determine the predictors of repeated measures of CD4 cell count change and to evaluate the shape of growth model, Latent Growth Model (LGM) and Covariate Latent Growth Model (CLGM) were considered and indicated in Figure3 and Figure4.

The SEM model (PROC CALIS) specifies latent variables, constant (intercept), initial value and rate of change. In Figure3, a constant is regressed on the latent variables to determine the mean initial value and mean rate of change (slope) across the time period. The latent variables are regressed on the measured variables to estimate structural slopes and rate of change. The error 
terms specified the amount of variance in each measured variables which is said to be CD4 cell count change. The disturbance terms in SEM measures the amount of unexplained variance for each latent variable and the correlation between disturbance terms indicated the relation between the unexplained variances.

In successive measures of CD4 cell count change, in Figure3, assume that CD4change_3 be the average observed value of CD4 cell count change data at the $(\mathrm{j}-3)^{\text {th }}$ visiting time,CD4change_2

be the average observed value of CD4 cell count change at the $(\mathrm{j}-2)^{\text {th }}$ visit, CD4change_1 be the average observed value of CD4 cell count at the $(\mathrm{j}-1)^{\text {th }}$ visit and CD4 change be the average observed value of CD4 cell count change data at the jth(current) visit.

Hence, assume (CD4change_3,CD4change_2,CD4change_1,CD4change) are repeated average measures of CD4 cell count change values in the consecutive visits for both male and female adult patients [21-24].

The repeated CD4 cell count change command indicates four repeated measures be renamed as average CD4change [25]. PROC CALIS for repeated measures of CD4 cell count change has no specific tests of significance. SEM using PROC CALIS specifies/considers measurement error[25]. For further information, the SAS command used for parameter estimation in PROC GLM and PROC CALIS is attached as additional material.

The LGM for PROC CALIS is indicated in Figure 3 and the parameter estimates are indicated in Table3.

\section{Figure2:}

In Figure3, assume that $k_{5}$ is a parameter between intercept and initial value $\left(\mathrm{F}_{1}\right)$ and $k_{6}$ be a parameter between intercept and rate of change $\left(\mathrm{F}_{2}\right)$.

Note that: the intercept is a constant equal to 1 , the parameters between initial value $\left(\mathrm{F}_{1}\right)$ and measured variables are assumed to be 1 [29]. Variances of measured variables are estimated at the four consecutive repeated measures of CD4 cell count change[30].

Structural slopes are fixed at 0 and 1 for CD4change_3 and CD4change_2 respectively and estimated for the CD4change_1 and CD4change [29]. Unmeasured (latent) variables are initial 
value $\left(\mathrm{F}_{1}\right)$ and rate of change $\left(\mathrm{F}_{2}\right)$. The constant intercept $(\mathrm{C})$ is regressed on the latent variables (initial value) to estimate the parameter $\left(k_{5}\right)$ and it also regressed on another latent variable (rate of change) to estimate a parameter $\left(k_{6}\right)[29]$.

The PROC CALIS code specifies the equations that would be solved simultaneously[31]. The parameters to be estimated are the structural slope between rates of change $\left(\mathrm{F}_{2}\right)$ and CD4change_ $1\left(k_{1}\right)$ and structural slopes between rates of change $\left(\mathrm{F}_{2}\right)$ and CD4change $\left(\mathrm{K}_{2}\right)$ [25].

The mean initial level $\left(k_{5}\right)$, the mean rates of change $\left(k_{6}\right)$, the error and disturbance variances (vare $\left.e_{4}, \operatorname{var} e_{3}, \operatorname{var} e_{2}, \operatorname{var} e_{1}, \operatorname{var} D_{1}, \operatorname{var} D_{2}\right)$ and covariance of the disturbance terms $\left(\mathrm{CD}_{1} D_{2}\right)$ were estimated using PROC CALIS [25].

The PROC CALIS estimated the structural slopes between rate of change $\left(\mathrm{F}_{2}\right)$ and CD4change_1 to be $k_{1}=2.08$, structural slopes between rate of change $\left(\mathrm{F}_{2}\right)$ and CD4change to be $k_{2}=2.89$. Hence, the four structural slopes initiated from $\mathrm{F}_{2}$ including the fixed slopes for CD4change_3, CD4change_2, CD4change_1 and CD4change were 0, 1, 2.08 and 2.89. The repeated measures ANOVA model was re-specified using PROC CLIS to test for linearity change.

Estimates of structural slopes $(0,1,2.08$, and 2.89) from PROC CALIS were replaced for the original linear contrast $(1,2,3,4)$ in PROC GLM code. PROC GLM tested for significance of mean differences in CD4 cell count change between repeated measures with a linear default model (levels 1, 2, 3, 4)[25]. The SEM (PROC CALIS) model estimated linear growth with PROC CALIS by fixing the rate of change at 0 and 1 (for CD 4 change_3\& CD4 change_2) respectively and estimated parameters for CD4change_1 and CD4change [27]. Therefore, the growth steps $(0,1,2.08,2.89)$ estimated by PROC CALIS indicated a linear growth trajectory of repeated outcome variable[20].

Table2 illustrates the parameter estimates and statistical tests (z-values) included in the PROC CALIS procedure.

Results from the PROC GLM and PROC CALIS analyses revealed that the two results were approximately similar. However, the SEM analysis using PROC CALIS proved more flexible and provided parameter estimation for rate of change, initial level, and variances that were not included in the PROC GLM analysis. This result revealed the advantage of PROC CALIS over traditional statistics (PROC GLM). 
Table2: Parameter estimates using PROC CALIS

\begin{tabular}{|l|l|l|l|}
\hline Parameters & Estimate & SE & z-value \\
\hline Mean initial value(F1) & 28.64 & 0.86 & 34.62 \\
\hline Mean Growth Rate(F2) & 14.65 & 0.64 & 22.10 \\
\hline Variance of initial value(D1) & 73.45 & 0.64 & 25.32 \\
\hline Variance of Growth Rate(D2) & 8.54 & 2.89 & 3.25 \\
\hline Covariance of initial value and Growth Rate & 7.86 & 5.45 & 2.08 \\
\hline Growth Scores & & & \\
\hline CD4change_3 & $0.00^{*}$ & - & - \\
\hline CD4change_2 & $1.00^{*}$ & - & - \\
\hline CD4change_1 & 2.08 & 0.06 & 25.31 \\
\hline CD4change & 2.89 & 0.08 & 26.28 \\
\hline Variance & & & \\
\hline \multirow{2}{|c}{$e_{4}$} & 21.62 & 6.97 & 28.66 \\
\hline$e_{3}$ & 22.74 & 2.54 & 6.58 \\
\hline$e_{1}$ & 16.35 & 4.05 & 4.31 \\
\hline
\end{tabular}

Note: * stands for fixed value

The baseline models (LGM) which did not include male as a covariate and a model included male (CLGM) as a covariate were estimated and evaluated for model fit and significance of estimated parameters. In a covariate model dummy variable (male) has been added to the baseline model as indicated in Figure4. A constant intercept (C) is also regressed on the covariate (male) in addition to initial value $\left(\mathrm{F}_{1}\right)$ and rate of growth $\left(\mathrm{F}_{2}\right)$.

\section{Figure3:}

In Figur4, assume that a parameter between the covariate male and $\mathrm{F}_{1}$ to be $k_{3}$ and between covariate male and $\mathrm{F}_{2}$ to be $k_{4}$, a parameter between a constant $(\mathrm{C})$ and $\mathrm{F}_{1}$ to be $k_{5}$, a parameter between intercept and $\mathrm{F}_{2}$ to be $k_{6}$ and a parameter between intercept and covariate male to be $k_{7}$. Similar to Figur3, it is given that the parameters originated in initial value $\left(F_{1}\right)$ to be fixed $(1)$ and parameters originated in rate of change $\left(\mathrm{F}_{2}\right)$ and terminated to CD4change_ 3 and 
CD4change_ 2 to be 0 and 1 respectively. Here, the covariate/dummy variable (male) is regressed on both initial values $\left(F_{1}\right)$ and growth rate $\left(F_{2}\right)$ [32]. The variable sex has been recorded into a variable "male" in Figure4.

The baseline model (LGM) showed acceptable fit on CFI (0.992). Unacceptable fit was found with chi-square (40.235, $\mathrm{df}=3, \mathrm{p}<0.0001)$ and RMSEA (0.188). The covariate model including male (CLGM) found acceptable fit for CFI (0.998) and unacceptable fit for chi-square (40.42, df $=5, \mathrm{p}<0.0001)$ and RMSEA (0.14). Values for fit indices changed a small amount with the addition of the covariate (male). The differences between males and females in the parameter estimates were also investigated.

Structural slopes in the baseline models (LGM) were 0, 1, 2.08, and 2.89. Growth steps can be determined by finding differences between structural slopes[33]. The growth steps for CLGM were equal to $0,1,0.61$, and $0.57(0-0,1-0,1.61-1$, and $2.18-1.61)$ respectively. Growth steps and structural slopes provide more information about the shape of the developmental curve[33].

Table2: parameter estimates from baseline model (LGM)

\begin{tabular}{|l|l|l|l|}
\hline Parameter & Estimate & SE & z-value \\
\hline Mean initial value(F1) & 19.93 & 0.319 & 63.62 \\
\hline Mean Growth Rate(F2) & 17.76 & 0.42 & 41.38 \\
\hline Variance of initial value(D1) & 23.15 & 2.64 & 7.32 \\
\hline Variance of Growth Rate(D2) & 22.54 & 2.19 & 3.55 \\
\hline Covariance of initial value and Growth Rate & 9.51 & 2.46 & 3.78 \\
\hline Growth Scores & & & \\
\hline CD 4change_3 & $0.00^{*}$ & - & - \\
\hline CD 4change_2 ${ }^{2}$ CD4change_1 $k_{1}$ & $1.00^{*}$ & - & - \\
\hline CD 4 change $k_{2}$ & 1.61 & 0.03 & 60.12 \\
\hline & 2.18 & 0.04 & 53.60 \\
\hline Variance & & & \\
\hline$e_{4}$ & 11.59 & 3.09 & 4.07 \\
\hline$e_{3}$ & $21 . .05$ & 2.08 & 10.58 \\
\hline$e_{2}$ & 17.15 & 2.65 & 6.50 \\
\hline$e_{1}$ & 54.52 & 5.62 & 9.84 \\
\hline
\end{tabular}

Note: * stands for fixed value 
The initial value (F1) and rate of change (F2) for Covariate Latent Growth Model (CLGM) were determined from baseline model (latent growth model) as follows. If male is equal to 1 $(\mathrm{sex}=$ male $)$, initial value $(\mathrm{F} 1)=19.93-0.37=19.56$ and rate of growth(F2) $=17.76-$ $1.61=16.15[32]$.

For female patient, male was equal to 0 and initial value $(\mathrm{F} 1)$ was equal to 19.93 , growth rate was equal to 17.76. Parameter estimates are shown in Table4. Hence, sex difference had insignificant effect for initial vales $\left(F_{1}\right)$ and growth rate $\left(F_{2}\right)$. Hence, females had more initial value and more growth rate as compared to males.

Table3: Parameter estimates for covariate model $(\mathrm{sex}=\mathrm{male})$

\begin{tabular}{|c|c|c|c|}
\hline Parameters & Estimate & SE & z-value \\
\hline Mean initial value(F1) & 19.56 & 0.43 & 46.62 \\
\hline Mean Growth Rate(F2) & 17.15 & 0.48 & 37.03 \\
\hline Variance of initial value(D1) & 23.16 & 3.64 & 6.36 \\
\hline Variance of Growth Rate(D2) & 21.54 & 2.63 & 8.25 \\
\hline Covariance of initial value and Growth Rate & 9.46 & 2.45 & 3.96 \\
\hline \multicolumn{4}{|l|}{ Growth Scores } \\
\hline CD4change_3 & $0.00 *$ & - & - \\
\hline CD4change_2 & $1.00 *$ & - & - \\
\hline CD4change_1 $1 k_{1}$ & 1.61 & 0.03 & 60.12 \\
\hline CD4change $k_{2}$ & 2.08 & 2.42 & 52.45 \\
\hline \multicolumn{4}{|l|}{ Variance } \\
\hline $\mathrm{e}_{4}$ & 12.62 & 3.09 & 4.05 \\
\hline $\mathrm{e}_{3}$ & 21.05 & 2.09 & 10.07 \\
\hline $\mathrm{e}_{2}$ & 17.05 & 2.63 & 6.50 \\
\hline$e_{1}$ & 55.72 & 5.71 & 9.71 \\
\hline Male(em) & 0.25 & 0.02 & 13.25 \\
\hline \multicolumn{4}{|l|}{ Covariate-initial value } \\
\hline F1 $\longleftarrow$ male $_{3}$ & -0.37 & 0.63 & -0.61 \\
\hline \multicolumn{4}{|l|}{ Covariate-rate of change } \\
\hline F2 $\longleftarrow$ male $k_{4}$ & -1.67 & 0.67 & -2.92 \\
\hline
\end{tabular}

Note1: * stands for fixed value;

Note2: Parameter estimates were conducted using SAS commands attached as additional materials. 
The covariate model helped to adjust baseline parameter estimates for initial value and growth rate. The change from the baseline model to covariate model can be calculated to provide a rough estimate of adjusted values. Hence, to compute adjusted initial value for male patients, the initial value at baseline parameter estimate, the product of proportion of male patients and parameter estimate for the regression of the covariate (male) on the latent construct (initial level) were considered. Hence, adjusted initial value $=19.93+(0.495)(-0.37)=19.93-0.18=19.75$.

The adjusted value of rate of growth was computed using growth rate at baseline parameter estimate plus the product of proportion of male and parameter estimate for regression of covariate (male) on latent construct (growth rate). Hence, adjusted value of rate of growth = $17.65+(0.495)(-1.67)=17.65-0.78=16.87$.

Calculation of a rough estimate of adjusted values for female patients was calculated by using the opposite direction (sign) for the parameter estimates[34]. Hence, the adjusted initial value for female patients was computed using initial value baseline parameter estimate, the product of proportion of female patients and parameter estimate for the regression of the covariate (male) with reverse direction on the latent construct (initial level). Adjusted initial value for female patient $=19.93-(0.505)(-0.37)=19.93+0.19=20.12$.

Using the same procedure, the adjusted rate of growth for female patients can be determined. The adjusted value of rate of growth for females was equal to growth rate in baseline parameter estimate minus the product of female proportion and parameter estimate for regression of covariate (male) on latent construct. Hence, adjusted growth rate value $=17.65-(0.505)(-1.67)$ $=17.65+0.84=18.49$.

This result indicates that both growth rates (F2) and initial value (F1) of females were greater than that of males. This means females had better progression rate (change) of CD4 cell count as compared to males.

\section{DISCUSSION}

In current investigation, the association of socio-demographic, individual characteristics and clinical variables were investigated using AMOS software. The result in this investigation revealed that Socio-demographic factors, economic factors and individual characteristics have direct and significant association with retention in HAART program. This findings is agreed with one of the previous investigation [35]. Similarly, Clinical factors such as baseline CD4 cell count, WHO stages and adherence level had direct and significant effect on HAART adherence 
competence. Hence, HIV positive adults with good adherence level, high baseline CD4 cell count and WHO stages of not stage IV had good HAART adherence competence. This result is similar with previously conducted research[36]. Retention in medication care had also direct and significant effect on HAART adherence competence which means patients which closely follow their prescribed medication given by the health staff had good adherence competence. This result agreed with previous researches [36, 37]. Finally, retention in medication care and adherence competence had direct and significant effect on the variable of interest (CD4 cell count change) which has similar argument with previous researches[35, 36].

The economic factors such as patients with cell phone and those who had high income associate with high retention in the medication care. Hence, patients with high income may use different alternatives to get pills and he/she also uses proper food adherence schedules for the treatment to be effective and this encourages the patient to attend the visits of health institution[38]. Cell phone of patients can play significant role in taking pills on time and to remind the date that the patient should visit the hospital and this has indirect effect on the status of CD4 cell count change. Cell phone helped patients to be HAART adherent because of its alarm (memory aid) for reminding the time pills are taken [39]. This finding is consistent with findings from another study [40] and suggests the need for making cell phones available to the needy HAART attendants. This finding is consistent with previously conducted research[9] .

Clinical factors such as patients' CD4 cells count significantly affected their retention of medication care. Patients with high baseline CD4 cell count encouraged the patient to be HAART adherent as compared to patients with less number of CD4 cell count[40-43]. This result indicates that clinical factors (baseline CD4 cell count and WHO stages) positively associated with retention of medication care.

The PROC CALIS command in current investigation helped to compute the adjusted value of latent variables (initial value and growth rate). The result of CLGM revealed that females had better initial value and growth rate as compared to males which is agreed with previous researches [40]. The potential reason for this may be the reach experience of females in taking pills for birth control leads good adherence and this further leads for better CD4 cell count progress. 


\section{CONCLUSION}

The analysis in the current investigation identified a certain group of patients, such as males and rural patients, patients without owner of cells phone, patients living without partners and aged patients were a relatively maximum risk of treatment response (CD4 cell count change). Poor adherent patients had low results in the variable of interests which indicates that adherence to HAART and CD4 cell count change are positively correlated to each other. Patients with good performance of adherence to medication had better CD4 cell count change. The current study indicated that the variable of interest (CD4 cell count change) increased over time. However, its progress was different for different groups such as males and females. Patients with high baseline CD4 cell count at registration for treatment had better progress of CD4 cell count in long term treatment.

The result in current investigation corroborates key factors like realistic assessment of patients' knowledge/level of education and understanding of the regimen, residence area of patients, age and sex of patients. The research endeavoured to identify certain groups that require special attention; and this helps to intervene in HAART program to be effective and elongate patients` lives with the virus

Consequently, due attention should be given to address the specific needs of each group of patients. Non-adherent patients in this long-term treatment program were at risk and should receive interventional treatment. Health related education should be given to patients to be good adherent and this leads for high progress of CD4 cell count change [44, 45].

Moreover, interventions need to be designed to promote early HIV testing and early enrollment of HIV infected individuals into ART services. Health related issues about socio-demographic, economic, individual characteristics and clinical factors, public awareness through advocacy and social mobilization should be included in the ART service. It is strongly recommended that underline the need for ART in HIV infected patients for immune reconstitution.

List of abbreviations: RMSEA $=$ Root Mean Square Error Analysis, HAART $=$ Highly Active antiretroviral therapy, ART = actively retroviral therapy, LGM = Latent Growth Model, CLGM = Covariate Latent Growth Model, HIV=human immunodeficiency virus, SEM= Structural Equation Modeling, $\mathrm{CFI}=$ Comparative Fit Indices. 


\section{DECLARATION SECTION}

Ethical approval and Consent for participants: Since the data was secondary and there was no chance of getting participants, consent for participants was not obtained from respondents. However, to get the secondary data from the hospital in the study area, Ethical clearance certificate had been obtained from two universities namely Bahir Dar University, Ethiopia with Ref $\neq$ RCS/1412/20012 and University of South Africa (UNISA), South Africa, Ref $\neq: 2015-S S R-$ $E R C_{-}$018. We can attach the ethical clearances certificate up on request.

Consent for publication: This manuscript has not been published elsewhere and is not under consideration by any other journal. All authors approved the final manuscript and agreed with its submission. We agreed about authorship and order of authors for this manuscript.

Availability of data and materials: We confirm that the data used for this study is available at corresponding authors and can be submitted upon request.

Competing interests: As no individual or institution funded this research, there is no conflict of financial interest between authors or between authors and institutions.

Funding: Not applicable

Authors' contributions: The first author wrote the proposal, develop data collection format, supervise the data collection process, analyzed and interpreted the data. The second and third authors participated in design and data analysis and critically read the manuscript and gave constructive comments for the betterment of the manuscript applying their reach experience. All authors contributed on manuscript preparation and discussed on order of authors.

Acknowledgement: Felege Hiwot Teaching and Specialized Hospital, Ethiopia is gratefully acknowledged for the data supplied in our health research.

Author's information: AST is an associate professor in the department of statistics at Bahir Dar University. Currently, he is a doctoral student in statistics department (University of South Africa) under the supervision of the second and third authors.. The second author (PN) is a senior Professor of the University of South Africa with many publications previously. The third author (TZ) is a senior Professor of college of mathematics, Statistics and Computer science at university of Kwazulu Natal. He has more than one hundred thirty (130) publications in reputable journals. All the three authors together had five previous publications using the same 
data with the current one and on the same study area. This will be the six ${ }^{\text {th }}$ article for our $\mathrm{PhD}$ paper. The previous five articles are;

1. Seyoum et al .(2016): AIDS Res Ther (2016) 13:36), DOI 10.1186/s12981-016-0119-6 Available on line:https://aidsrestherapy.biomedcentral.com/articles../Comparison-of-quasi-Poisson-andnega..

2. Seyoum et al. AIDS Res Ther (2017): AIDS Res Ther (2017): DOI 10.1186/s12981-017-0141-3). Available on line: https://aidsrestherapy.biomedcentral.com/articles/.../s12981-017-0141

3. Tegegne et al. (2018): Journal: BMC Infectious Diseases (2018):18:83, DOI 10.1186/s12879-018-2977-0 Available on line :https://www.ncbi.nlm.nih.gov/pmc/articles/PMC5819083

4. Tegegne et al (2018): Journal:BMC Infectious Diseases (2018) 18:197, https://doi.org/10.1186/s12879-018-3108-7). Available on line: https://bmcinfectdis.biomedcentral.com/articles/10.../open-peer-review

5. Awoke Seyoum et al. (2019):AJOL, Ethiop. J. Sci. \& Technol. 11(3): 165-193,2018: Available on line: https://www.ajol.info/index.php/ejst/article/download/.../174355

\section{REFERENCES}

1. Indravudh, P.P., A.T. Choko, and E.L. Corbett, Scaling up HIV self-testing in subSaharan Africa: a review of technology, policy and evidence. Current opinion in infectious diseases, 2018. 31(1): p. 14.

2. Wondimeneh, Y., et al., HIV and Malaria Infections and Associated Risk Factors Among Febrile Illness Patients in Northwest Ethiopia. Türkiye Parazitolojii Dergisi, 2018. 42(3): p. 180.

3. Tadesse, S., F. Enqueselassie, and S.H. Gebreyesus, Estimating the spatial risk of tuberculosis distribution in Gurage zone, southern Ethiopia: a geostatistical kriging approach. BMC public health, 2018. 18(1): p. 783.

4. Beyene, M.B. and H.B. Beyene, Predictors of late HIV diagnosis among adult people living with HIVIAIDS who undertake an initial CD4 T cell evaluation, northern Ethiopia: a case-control study. PloS one, 2015. 10(10): p. e0140004.

5. Langebeek, N., et al., Predictors and correlates of adherence to combination antiretroviral therapy (ART) for chronic HIV infection: a meta-analysis. BMC medicine, 2014. 12(1): p. 142.

6. Do, N.T., et al., Psychosocial factors affecting medication adherence among HIV-1 infected adults receiving combination antiretroviral therapy (cART) in Botswana. AIDS research and human retroviruses, 2010. 26(6): p. 685-691.

7. Nosyk, B., et al., Characterizing retention in HAART as a recurrent event process: insights into 'cascade churn'. AIDS (London, England), 2015. 29(13): p. 1681.

8. Howard, A.A., et al., A prospective study of adherence and viral load in a large multicenter cohort of HIV-infected women. Aids, 2002. 16(16): p. 2175-2182.

9. Amberbir, A., et al., Predictors of adherence to antiretroviral therapy among HIVinfected persons: a prospective study in Southwest Ethiopia. BMC public health, 2008. 8(1): p. 265.

10. Alvarez-Uria, G., et al., Entry, retention, and virological suppression in an HIV cohort study in India: description of the cascade of care and implications for reducing HIV-

19 | P a g e 
related mortality in low-and middle-income countries. Interdisciplinary perspectives on infectious diseases, 2013. 2013.

11. Belle, D., Poverty and women's mental health. American psychologist, 1990. 45(3): p. 385.

12. Alok, R., et al., Problem-focused coping and self-efficacy as correlates of quality of life and severity of fibromyalgia in primary fibromyalgia patients. JCR: Journal of Clinical Rheumatology, 2014. 20(6): p. 314-316.

13. Okonji, J.A., et al., CD4, viral load response, and adherence among antiretroviral-naive breast-feeding women receiving triple antiretroviral prophylaxis for prevention of mother-to-child transmission of HIV in Kisumu, Kenya. JAIDS Journal of Acquired Immune Deficiency Syndromes, 2012. 61(2): p. 249-257.

14. Schwimmer, J.B., T.M. Burwinkle, and J.W. Varni, Health-related quality of life of severely obese children and adolescents. Jama, 2003. 289(14): p. 1813-1819.

15. Sagarduy, J.L.Y., et al., Psychological model of ART adherence behaviors in persons living with HIV/AIDS in Mexico: a structural equation analysis. Revista de saude publica, 2017. 51: p. 81.

16. Rao, D., et al., A structural equation model of HIV-related stigma, depressive symptoms, and medication adherence. AIDS and Behavior, 2012. 16(3): p. 711-716.

17. Shmueli, A., Socio-economic and demographic variation in health and in its measures: the issue of reporting heterogeneity. Social Science \& Medicine, 2003. 57(1): p. 125-134.

18. Guerrero, M., J. Rialp, and D. Urbano, The impact of desirability and feasibility on entrepreneurial intentions: A structural equation model. International Entrepreneurship and Management Journal, 2008. 4(1): p. 35-50.

19. Guerrero, J.M., et al., Hierarchical control of droop-controlled AC and DC microgridsA general approach toward standardization. IEEE Transactions on industrial electronics, 2010. 58(1): p. 158-172.

20. Katunarić, V., Od egalitarnog sindroma do izvrsnosti: $O$ načinima legitimiranja društvenih nejednakosti. Politička misao, 2011. 48(03): p. 11-34.

21. Hoyle, R.H., The structural equation modeling approach: Basic concepts and fundamental issues. 1995.

22. Roth, D.L., et al., Life events, fitness, hardiness, and health: a simultaneous analysis of proposed stress-resistance effects. Journal of personality and social psychology, 1989. 57(1): p. 136.

23. Duncan, T.E., et al., Latent variable modeling of longitudinal and multilevel substance use data. Multivariate Behavioral Research, 1997. 32(3): p. 275-318.

24. Schlebusch, L. and R.D. Govender, Age, gender and suicidal ideation following voluntary HIV counseling and testing. International journal of environmental research and public health, 2012. 9(2): p. 521-530.

25. Suhr, D., The basics of structural equation modeling. Presented: Irvine, CA, SAS User Group of the Western Region of the United States (WUSS), 2006.

26. Marsh, H.W. and D. Hocevar, Application of confirmatory factor analysis to the study of self-concept: First-and higher order factor models and their invariance across groups. Psychological bulletin, 1985. 97(3): p. 562.

27. MacCallum, R.C. and J.T. Austin, Applications of structural equation modeling in psychological research. Annual review of psychology, 2000. 51(1): p. 201-226. 
28. Hu, L.t. and P.M. Bentler, Cutoff criteria for fit indexes in covariance structure analysis: Conventional criteria versus new alternatives. Structural equation modeling: a multidisciplinary journal, 1999. 6(1): p. 1-55.

29. Kline, R.B., Principles and practice of structural equation modeling. 2015: Guilford publications.

30. Hair, J.F., et al., The use of partial least squares structural equation modeling in strategic management research: a review of past practices and recommendations for future applications. Long range planning, 2012. 45(5-6): p. 320-340.

31. Kline, R.B., Principles and practice of structural equation. Modeling.(3nd, 2011.

32. Karagöz, Y., SPSS 21.1 uygulamalı biyoistatistik: tıp, eczacıllk, diş hekimliği ve sağlık bilimleri için. 2014: Nobel Akademik Yayıncılık.

33. Suhr, D.D., An investigation of mathematics and reading achievement of 5-through 14year olds using latent growth curve methodology. 2000.

34. Borsboom, D., G.J. Mellenbergh, and J. Van Heerden, The theoretical status of latent variables. Psychological review, 2003. 110(2): p. 203.

35. Bayou, T., et al., Factors determinant for change of initial antiretroviral treatment regimen among patients on ART follow-up clinic of Mekelle Hospital, Mekelle, Ethiopia. Int J Basic Clin Pharmacol, 2014. 3(1): p. 44-9.

36. Ezeamama, A.E., et al., Age, sex, and nutritional status modify the CD4+ T-cell recovery rate in HIV-tuberculosis co-infected patients on combination antiretroviral therapy. International Journal of Infectious Diseases, 2015. 35: p. 73-79.

37. Ye, R.-H., et al., Studies on the determinants and changes related to the natural CD4 (+) $T$ cell counts among antiretroviral treatment-naive HIV/AIDS patients in Dehong prefecture, Yunnan province. Zhonghua liu xing bing xue za $\mathrm{zhi}=$ Zhonghua liuxingbingxue zazhi, 2011. 32(9): p. 882-887.

38. Kipp, A.M., et al., Socio-demographic and AIDS-related factors associated with tuberculosis stigma in southern Thailand: a quantitative, cross-sectional study of stigma among patients with TB and healthy community members. BMC Public Health, 2011. 11(1): p. 675.

39. Maqutu, D., et al., Determinants of optimal adherence over time to antiretroviral therapy amongst HIV positive adults in South Africa: a longitudinal study. AIDS and Behavior, 2011. 15(7): p. 1465-1474.

40. Florence, E., et al., Factors associated with a reduced CD4 lymphocyte count response to HAART despite full viral suppression in the EuroSIDA study. HIV medicine, 2003. 4(3): p. 255-262.

41. Ebonyi, A.O., et al., Factors associated with a low CD4 count among HIV-1 infected patients at enrolment into HAART in Jos, Nigeria. British Journal of Medicine and Medical Research, 2014. 4(13): p. 2536.

42. Montarroyos, U.R., et al., Factors related to changes in CD4+ T-cell counts over time in patients living with HIV/AIDS: a multilevel analysis. PloS one, 2014. 9(2): p. e84276.

43. Smith, C.J., et al., Factors influencing increases in CD4 cell counts of HIV-positive persons receiving long-term highly active antiretroviral therapy. Journal of Infectious Diseases, 2004. 190(10): p. 1860-1868.

44. Adams, M. and A. Luguterah, Longitudinal analysis of change in CD4+ cell counts of $H I V-1$ patients on antiretroviral therapy (ART) in the Builsa district hospital. European Scientific Journal, 2013. 9(33). 
45. Asfaw, A., et al., CD4 cell count trends after commencement of antiretroviral therapy among HIV-infected patients in Tigray, Northern Ethiopia: a retrospective crosssectional study. PloS one, 2015. 10(3): p. e0122583.

Figure1: Hypothetical model of relationship between observed and latent variables with the variable of interest (CD4change)

Figure4: Path Analysis of predictor variables for CD4 cell count change after estimates of parameters and error terms.

Figure5: Latent Growth Model (LGM) - CD4 cell count change

Figure6: Covariate Latent Growth Model (CLGM) 
Figures

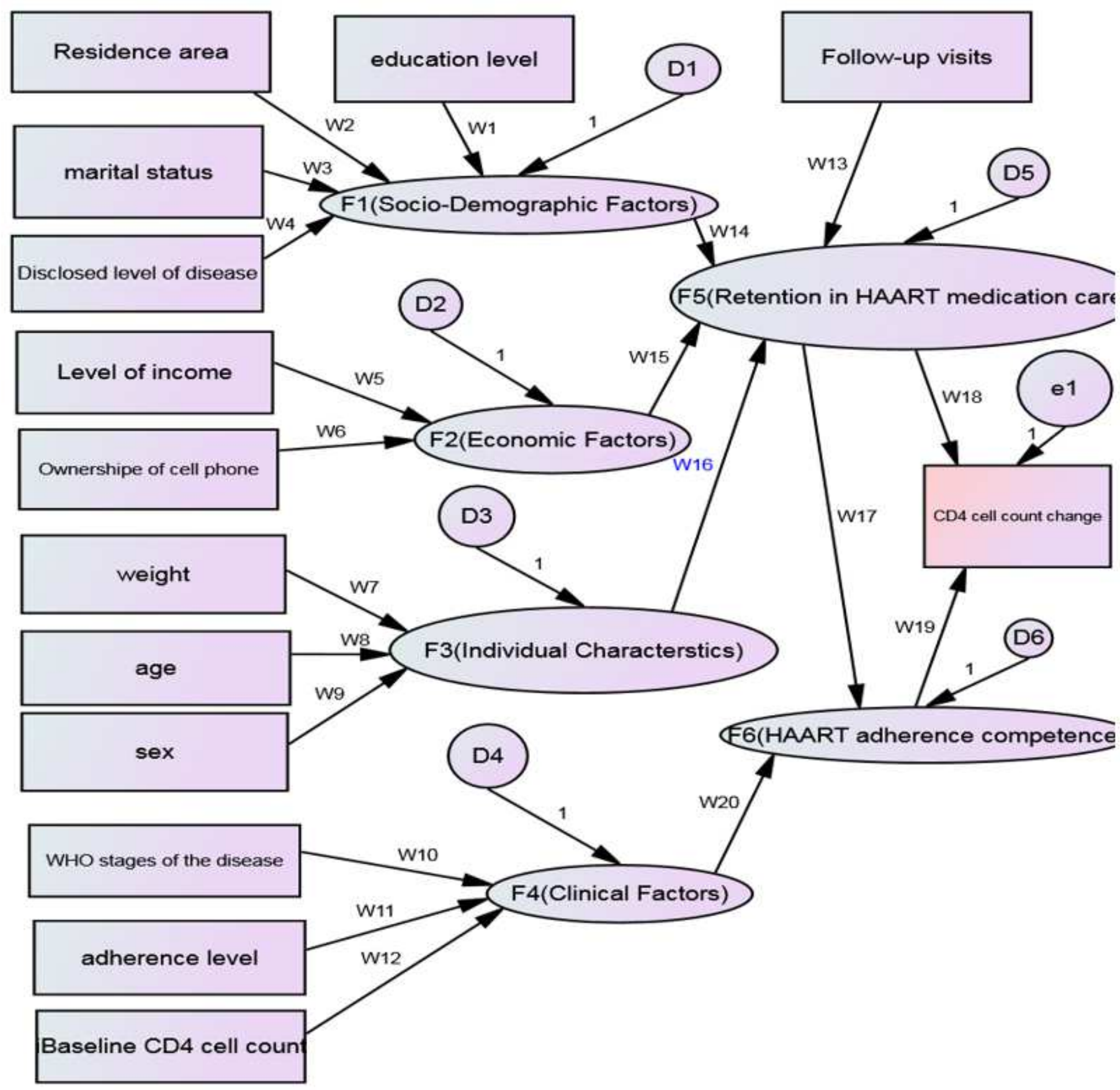

\section{Figure 1}

Hypothetical model of relationship between observed and latent variables with the variable of interest (CD4change) 


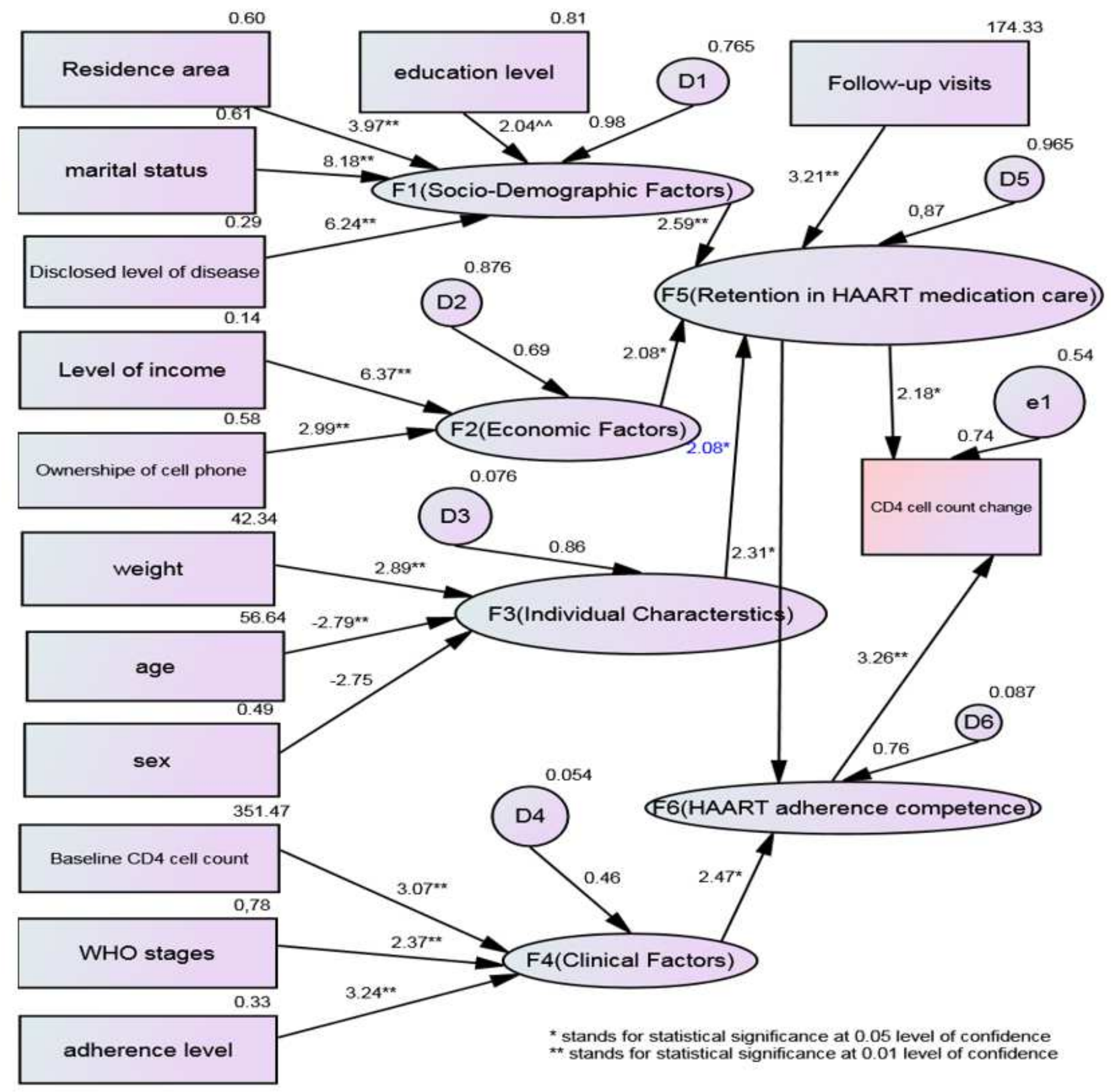

Figure 2

Path Analysis of predictor variables for CD4 cell count change after estimates of parameters and error terms. 


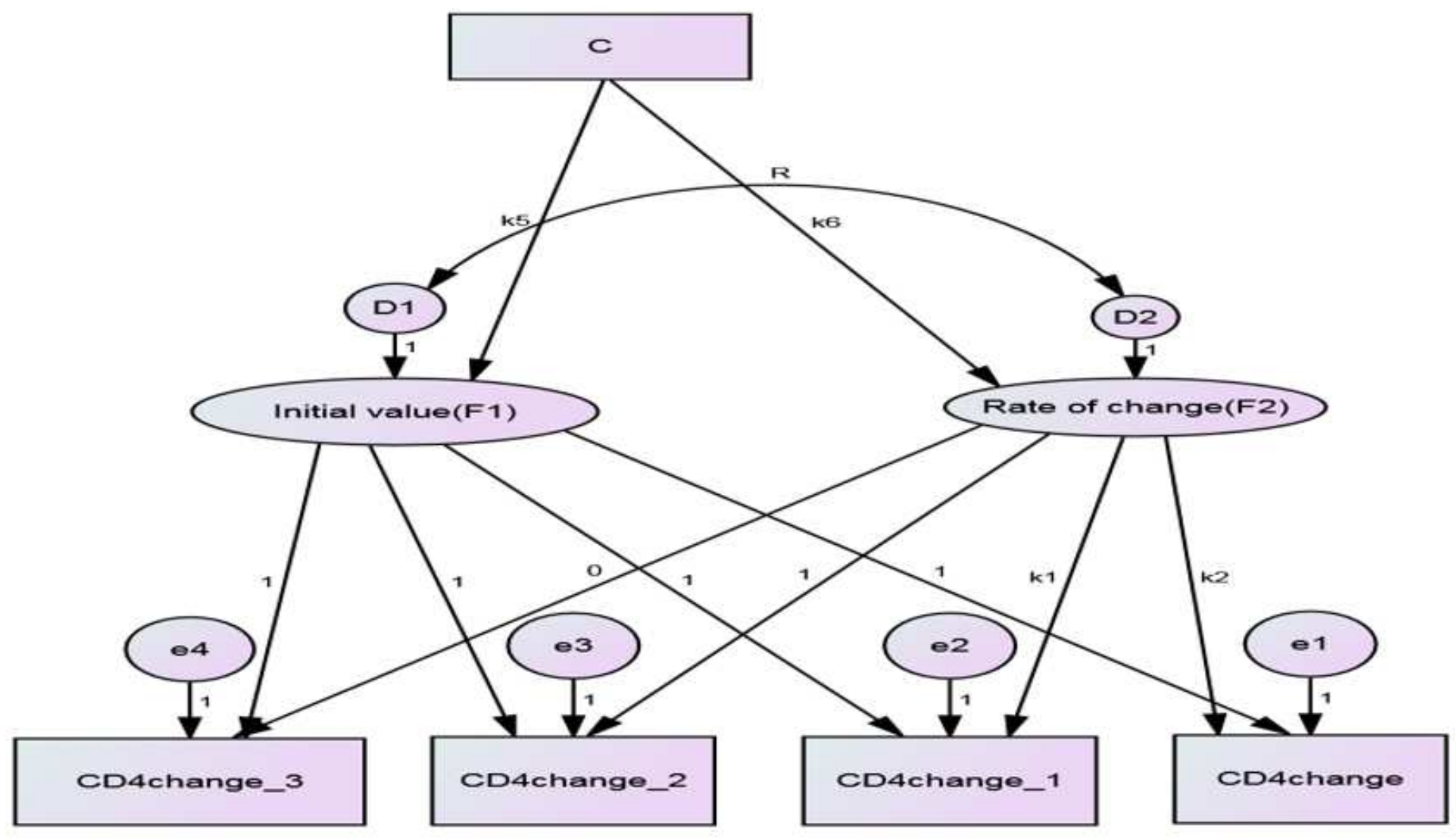

Figure 3

Latent Growth Model (LGM) - CD4 cell count change 


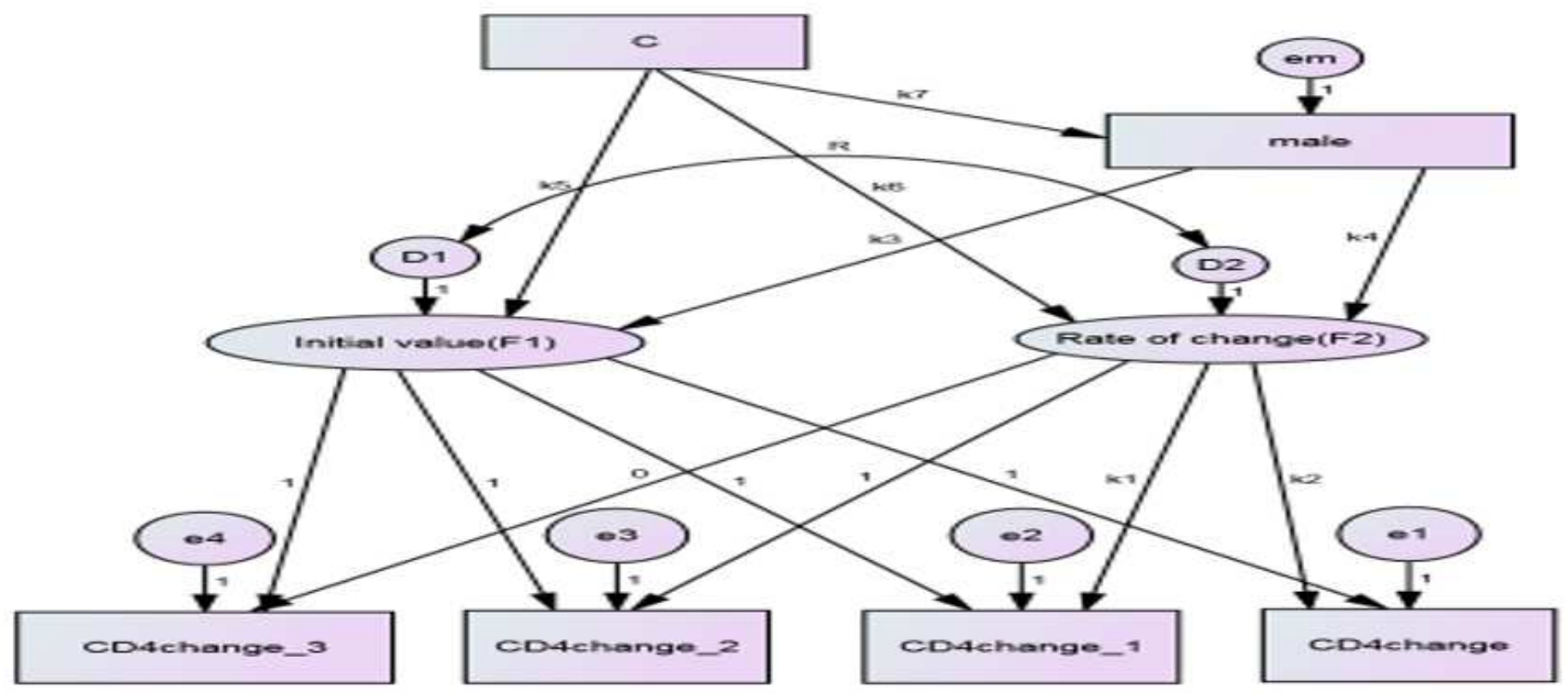

Figure 4

Covariate Latent Growth Model (CLGM)

\section{Supplementary Files}

This is a list of supplementary files associated with this preprint. Click to download.

- TheSASPROCCALIScommands.docx 